\title{
PERANCANGAN APLIKASI VALIDASI ABSENSI UJIAN AKHIR SEMESTER MAHASISWA MENGGUNAKAN QUICK RESPONSE (QR) CODE
}

\author{
Ambar Safaatun ${ }^{1}$, Ambar Tri Hapsari' ${ }^{2}$, Aswin Fitriansyah ${ }^{3}$ \\ Program Studi Informatika, Fakultas Teknik dan Ilmu Komputer, Universitas Indraprasta PGRI \\ Jalan Raya Tengah No 80, Kelurahan Gedong, Pasar Rebo, Jakarta Timur \\ safaa.ambar@gmail.com ${ }^{1}$, ambar.trihapsari@gmail.com. ${ }^{2}$, aswin.fitriyansyah@gmail.com ${ }^{3}$
}

\begin{abstract}
Abstrak
Tujuan sistem validasi kehadiran mahasiswa dalam ujian akhir semester menggunakan Quick Response (QR) Code adalah mengembangkan sistem validasi kehadiran Mahasiswa pada saat Ujian Akhir Semester (UAS). Dengan menggunakan Quick Response $(Q R)$ Code dapat meningkatkan akurasi kehadiran dan mengurangi kecurangan dengan memanfaatkan jasa orang lain untuk mengerjakan ujian dan menyamar sebagai peserta ujian yang sebenarnya dengan menerima imbalan uang (joki). Dan harapan Peneliti juga untuk mempermudah pengawas ujian dalam melakukan validasi kehadiran mahasiswa pada saat Ujian Akhir Semester (UAS). Metode penelitian yang digunakan untuk menganalisis proses validasi kehadiran peserta Ujian Akhir Semester (UAS) ini adalah metode observasi, studi literature dan wawancara. Peneliti juga menggunakan pendekatan struktural dalam menyusun langkah-langkah pengembangan sistem. Setelah peneliti menganalisis masalah yang terjadi pada saat pelaksanaan Ujian Akhir Semester (UAS) di Universitas Terbuka, akhirnya peneliti menarik simpulan dengan adanya sistem ini, masalah pelanggaran tata tertib dalam pelaksanaan Ujian Akhir Semester (UAS) dengan meningkatkan akurasi kehadiran sehingga mengurangi celah kecurangan tersebut. Masalah mahasiswa tidak membawa kartu identitas yang menyulitkan proses validasi peserta ujian pada saat pelaksanaan Ujian Akhir Semester (UAS) teratasi dengan adanya Quick Response $(Q R)$ Code serta mempermudah pengawas ujian dalam melakukan validasi kehadiran mahasiswa saat Ujian Akhir Semester (UAS) beserta presensi secara real time.
\end{abstract}

Kata Kunci : Sistem Informasi, Validasi Kehadiran Mahasiswa, Ujian Akhir Semester (UAS), Quick Response (QR) Code

\begin{abstract}
The purpose of validation system of student attendance in final semester exam using Quick Response (QR) Code is to develop the student attendance validation system at the end of Semester exam (UAS). Using Quick Response $(Q R)$ Code can improve attendance accuracy and reduce fraud by utilizing other people's services to work on exams and impersonate actual exam participants by accepting money rewards (joki). And the hope of researchers also to facilitate the examination supervisor in conducting validation of student attendance at the end of Semester exam (UAS). The research method used to analyze the validation process of the participants of the final Semester exam (UAS) is an observation method, literature research and interviews. The researchers use a structural approach in drafting system development measures. After the researchers analyzed the problems that occurred during the final Semester exam (UAS) at the University terbuka, the researchers finally drew a conclusion to the existence of this system, a problem of code of conduct violations in the implementation of the final Semester exam ( The accuracy of attendance, thus reducing the gap in fraud. Students ' problems do not carry identity cards that complicate the test participant validation process at the time of the Semester final Exam (UAS) is resolved by the presence of Quick Response $(Q R)$ Code and facilitate test supervisors in the validation Student attendance during the final Semester exam (UAS) and in real time.
\end{abstract}

Keyword : Information system, Validation of Student Absence, Final Examination, Quick Response (QR) Code

\section{PENDAHULUAN}

Perkembangan teknologi informasi di dunia semakin cepat, khususnya pada teknologi perangkat bergerak dan internet. Kebutuhan masyarakat terhadap layanan teknologi berbasis IT sangat bervariatif. Akses dan pengambilan informasi dikatakan semakin mudah dan cepat diakses melalui penggunaan perangkat bergerak dan web. Perkembangan ini juga mempengaruhi data sebagai validasi menggantikan kode sandi (password). Validasi merupakan sebuah proses yang wajib ada 
dimana diperlukan sebuah kebenaran data atau informasi, salah satunya adalah proses validasi kehadiran. (Nurrohman et al., 2017)

Seperti institusi pendidikan pada umumnya Universitas Terbuka juga melakukan kegiatan evaluasi. Hasil belajar mahasiswa dalam satu semester diukur melalui Ujian Akhir Semester (UAS). Ada dua bentuk UAS yaitu UAS tertulis dan UAS Online. Bentuk soal UAS tertulis dapat berupa tes objektif (pilihan ganda) atau tes uraian (essay). Pada beberapa program studi, UAS juga diberikan dalam bentuk ujian lisan (mata kuliah Speaking/Berbicara), dan menyimak (mata kuliah Listening/Menyimak).

Dalam pelaksanaanya, masih terdapat beberapa pelanggaran tata tertib ujian yang dilakukan oleh mahasiswa diantaranya, pelanggaran joki yaitu orang yang mengerjakan ujian untuk orang lain dengan menyamar sebagai peserta ujian yang sebenarnya dan menerima imbalan uang. Tujuannya adalah agar mahasiswa yang bersangkutan tetap mendapatkan nilai walaupun tidak hadir dalam ujian. Hal ini menimbulkan celah kelemahan pada pelaksanaan Ujian Akhir Semester (UAS) yaitu terjadi kecurangan atau pelanggaran tata tertib. Oleh karena itu, untuk mengantisipasi terjadinya kecurangan berupa joki maka diperlukan suatu sistem yang dapat meningkatkan akurasi kehadiran Mahasiswa dalam Ujian Akhir Semester (UAS).

Penggunaan metode Quick Response ( $Q R)$ Code pada sistem ini diharapkan dapat membuat sistem validasi kahadiran Mahasiswa dalam Ujian Akhir Semester (UAS) menjadi lebih mudah dan dapat meningkatkan akurasi kehadiran karena pengawas ujian hanya akan menempelkan Kartu Tanda Peserta Ujian (KTPU) Mahasiswa pada aplikasi mobile QR Code Scanner yang telah tersedia informasi berupa data pribadi mahasiswa yang bersangkutan beserta jadwal ujian mahasiswa tersebut, kemudian hasil inputan $Q R$ Code akan masuk pada database dan akan menjadi acuan sebagai validasi kehadiran mahasiswa dalam Ujian Akhir Semester (UAS).

\section{PENELITIAN RELEVAN}

Pendekatan penelitian berkaitan dengan tujuan utama penelitian, apakah penelitian bermaksud untuk menjelaskan hasil pengukuran suatu variable apa adanya atau membandingkan antara aspek yang diteliti ataupun menghubungkan antara variable. Dalam melakukan penelitian tentang Sistem Validasi Kehadiran Ujian Akhir Semester (UAS) Mahasiswa Universitas Terbuka Menggunakan $Q R$ Code, peneliti menggunakan bahan referensi dari berbagai sumber, antara lain dari jurnal yang relevan dengan penelitian yang peneliti lakukan.

Penelitian oleh Adigunawan Wijaya dan A. Gunawan dengan judul Penggunaan tentang $Q R$ Code Sarana Penyampaian Promosi dan Informasi Kebun Binatang Berbasis Android. Hasil Penelitian Aplikasi penggunaan $Q R$ Code sarana penyampaian promosi dan informasi di kebun binatang berbasis android berhasil dibangun dengan menggunakan zxing library. Penggunaan aplikasi $Q R$ Code ini memberikan kemudahan bagi pengunjung kebun binatang karena akses informasi dan promosi jauh lebih efektif dan fleksibel bagi pengunjung, karena tidak perlu lagi akses beberapa kali untuk mendapatkan informasi dan promos. Dengan adanya aplikasi $Q R$ Code pengelola kebun binatang dapat memanfaatkan dan menggunakan sebagai media informasi dan media promosi kepada pengunjung kebun binatang.

Penelitian oleh Mukhamad Taqwa Nuddin dan Diana Laily Fithri dengan judul Sistem Absensi Asisten Dosen Menggunakan $Q R$ Code Scanner Berbasis Android pada Program Studi Sistem Informasi Unversitas Muria Kudus dengan hasil penelitian Perancangan yang dilakukan telah menghasilkan sebuah sistem absensi asisten dosen menggunakan $Q R$ Code Scanner berbasis android yang dapat memproses absensi dan pengelolaan horor asisten dosen. Implementasi Sistem Absensi Asisten Dosen Menggunakan QR Code Scanner Berbasis Android ini menghasilkan informasi absen asisten dosen yang tepat karena tercantum waktu dan tidak bisa dirubah. Data absen yang telah dilakukan dapat dikelola laboran agar asisten dosen dapat menerima honor lebih cepat daripada sebelumnya. 


\section{METODE PENELITIAN}

Metode yang digunakan dalam penelitian ini adalah metode deskriptif yaitu metode yang dilakukan dengan cara menganalisis, menjelaskan dan merancang suatu sistem dari bahan-bahan yang tersedia. Peneliti melakukan analisis terhadap proses-proses validasi kehadiran peserta Ujian Akhir Semester (UAS) di Universitas Terbuka, mulai dari mengidentifikasi masalah-masalah yang terjadi pada saat pelaksanaan Ujian Akhir Semester (UAS) serta bagaimana cara mengantisipasi mahasiswa yang tidak membawa kartu identitas sehingga menyulitkan proses validasi peserta ujian pada saat pelaksanaan Ujian Akhir Semester (UAS). Hal ini untuk mengetahui penyebab masih terdapatnya beberapa pelanggaran tata tertib ujian yang dilakukan oleh mahasiswa diantaranya, pelanggaran joki yaitu orang yang mengerjakan ujian untuk orang lain dengan menyamar sebagai peserta ujian yang sebenarnya dan menerima imbalan uang.

Dengan adanya permasalahan diatas, maka peneliti merancang sebuah sistem validasi kehadiran menggunakan Quick Response $(Q R)$ Code yang diharapkan dapat membuat sistem validasi kahadiran Mahasiswa dalam Ujian Akhir Semester (UAS) menjadi lebih mudah dan dapat meningkatkan akurasi kehadiran.

Metode penelitian ini bertujuan untuk mengumpulkan informasi beserta pengumpulan data-data yang diperlukan dalam penelitian sehingga mendapatkan data-data yang akurat dan dapat digunakan untuk menunjang proses perancangan sistem validasi kehadiran mahasiswa Ujian Akhir Semester (UAS).

\section{HASIL DAN PEMBAHASAN \\ Analisa Permasalahan}

Dalam pelaksaan Ujian Akhir Semester (UAS) pada Univeristas Terbuka masih terdapat pelanggaran tata tertib ujian yang dilakukan oleh mahasiswa di antaranya, pelanggaran joki yaitu orang yang menyamar sebagai perserta ujian yang sebenarnya dan menerima imbalan uang tujuannya adalah agar mahasiswa yang bersangkuran tetap mendapatkan nilai meskipun tidak hadir dalam ujian, hal ini menimbulkan celah kelemahan pada pelaksanaan Ujian Akhir Semester (UAS) yaitu terjadi kecurangan atau pelanggran tata tertib. Oleh karena itu untuk mengantisipasi kecurangan berupa joki maka di perlukan suatu sistem yang dapat meningkatkan akurasi kehadiran mahasiswa dalam Ujian Akhir Semester (UAS)

Dari permasalahan di atas peneliti mengambil kesimpulan atas permasalahan yang ada diantaranya:

1. Masih terdapat joki (orang mengerjakan ujian untuk orang lain dengan menyamar sebagai peserta ujian yang sebenarnya dan menerima imbalan uang) dalam pelaksanaan Ujian Akhir Semester (UAS).

2. Masih terdapat peserta Ujian Akhir Semester (UAS) yang tidak membawa kartu identitas sehingga menyulitkan proses validasi peserta ujian.

3. Presensi kehadiran pada Ujian Akhir Semester (UAS) di Universitas Terbuka masih dilakukan secara manual.

\section{Alternatif Penyelesaian Masalah}

Berdasarkan analisa sistem yang sedang berjalan saat ini peneliti melihat kelemahan-kelemahan dan pokok permasalahan yang terdapat pada sistem validasi mahasiswa ujian akhir semester di Universitas Terbuka, maka peneliti dapat menyarankan beberapa alternatif permasalahan yang dapat digunakan :

1) Membuat sistem validasi kehadiran untuk mengantisipasi terjadinya kecurangan berupa joki dalam pelaksanaan ujian akhir semester.

2) Untuk mengatisipasi terjadinya mahasiswa yang tidak membawa kartu identitas peserta ujian sehingga meyulitkan petugas ruang ujian, maka peneliti membuat sistem validasi kehadiran mahasiswa ujian akhir ini menggunakan Quick Response $(Q R)$ Code diharapkan dapat mempermudah dan meningkatkan akurasi saat melakukan validasi. 
3) Guna menunjang kecepatan dalam mengetahui informasi mahasiswa yang telah mengikuti Ujian Akhir Semester (UAS) maka dibuatlah sebuah sistem presensi yang sudah terkomputerisasi.

\section{Unified Modelling Language (UML) Sistem Yang Diusulkan}

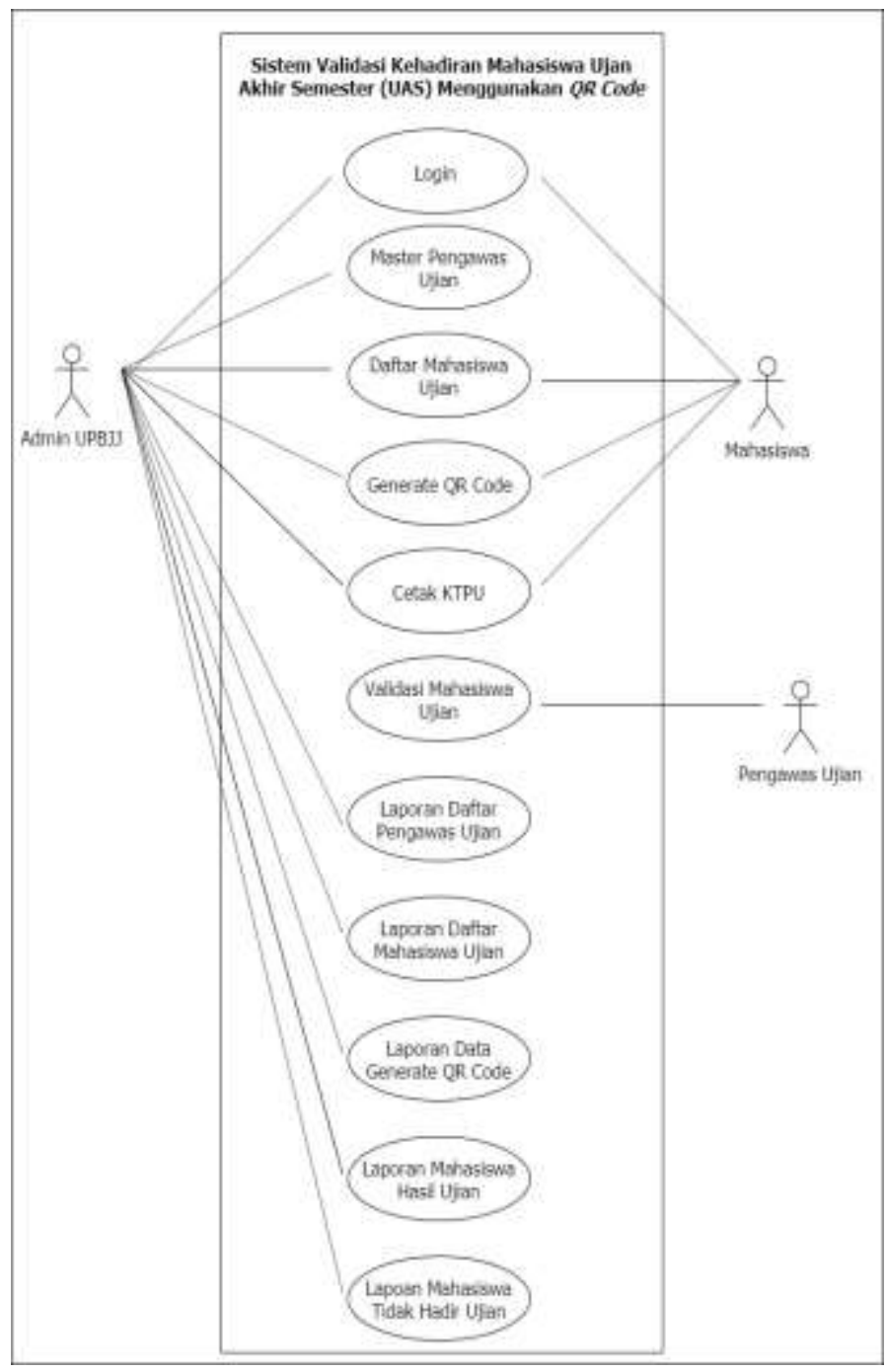

Gambar 1. Use Case Diagram

Use Case Diagram atau model fungsional dari sistem validasi kehadiran mahasiswa Ujian Akhir Semester (UAS) yang diusulkan menggambarkan secara keseluruhan terhadap apa saja yang dilakukan oleh sistem yang akan dirancang dan siapa saja yang berhubungan dengan sistem terebut. Pada gambar 1 diatas dapat dilihat bahwa sistem validasi kehadiran mahasiswa Ujian Akhir Semester (UAS) meiliki tiga aktor yaitu Admin UPBJJ, Mahasiswa dan Pengawas Ujian yang masing-masing memiliki wewenang dan tanggung jawab berbeda-beda. 
Jurnal Riset dan Aplikasi Mahasiswa Informatika (JRAMI)

Vol 미 No OI Tahun 2020

e-ISSN : $2715-8756$

\section{Activity Diagram}

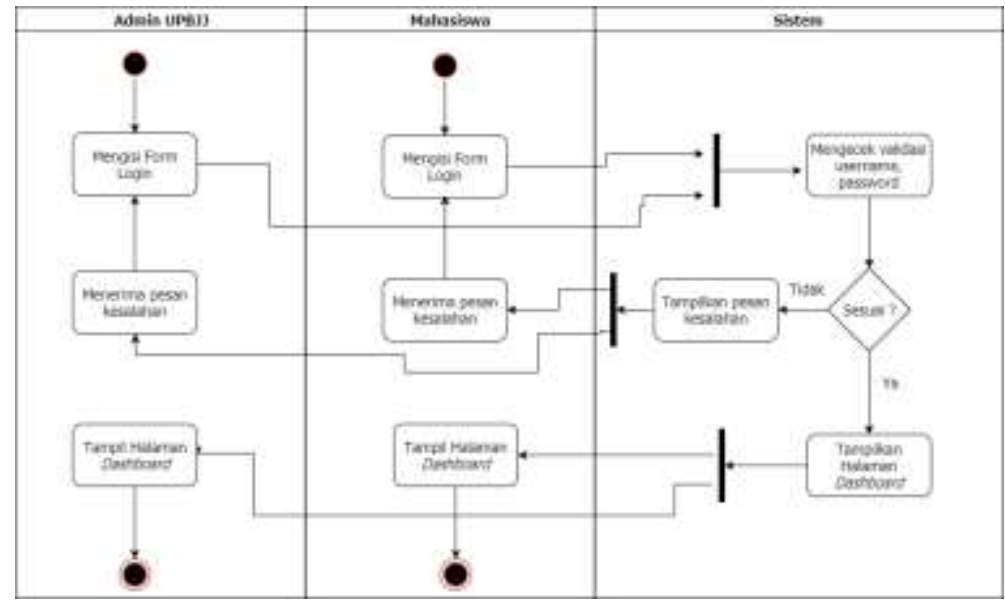

Gambar 2. Activity diagram login

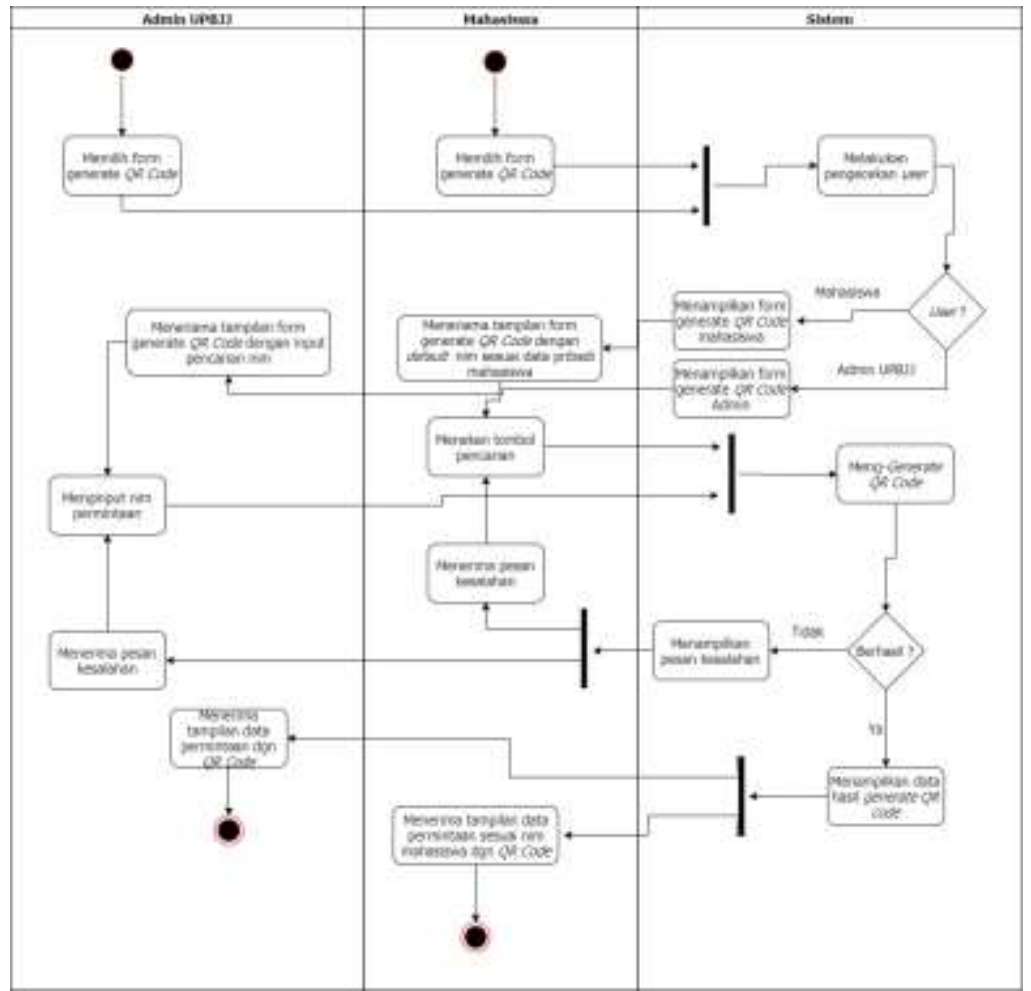

Gambar 3. Activity diagram generate $Q R$ Code 


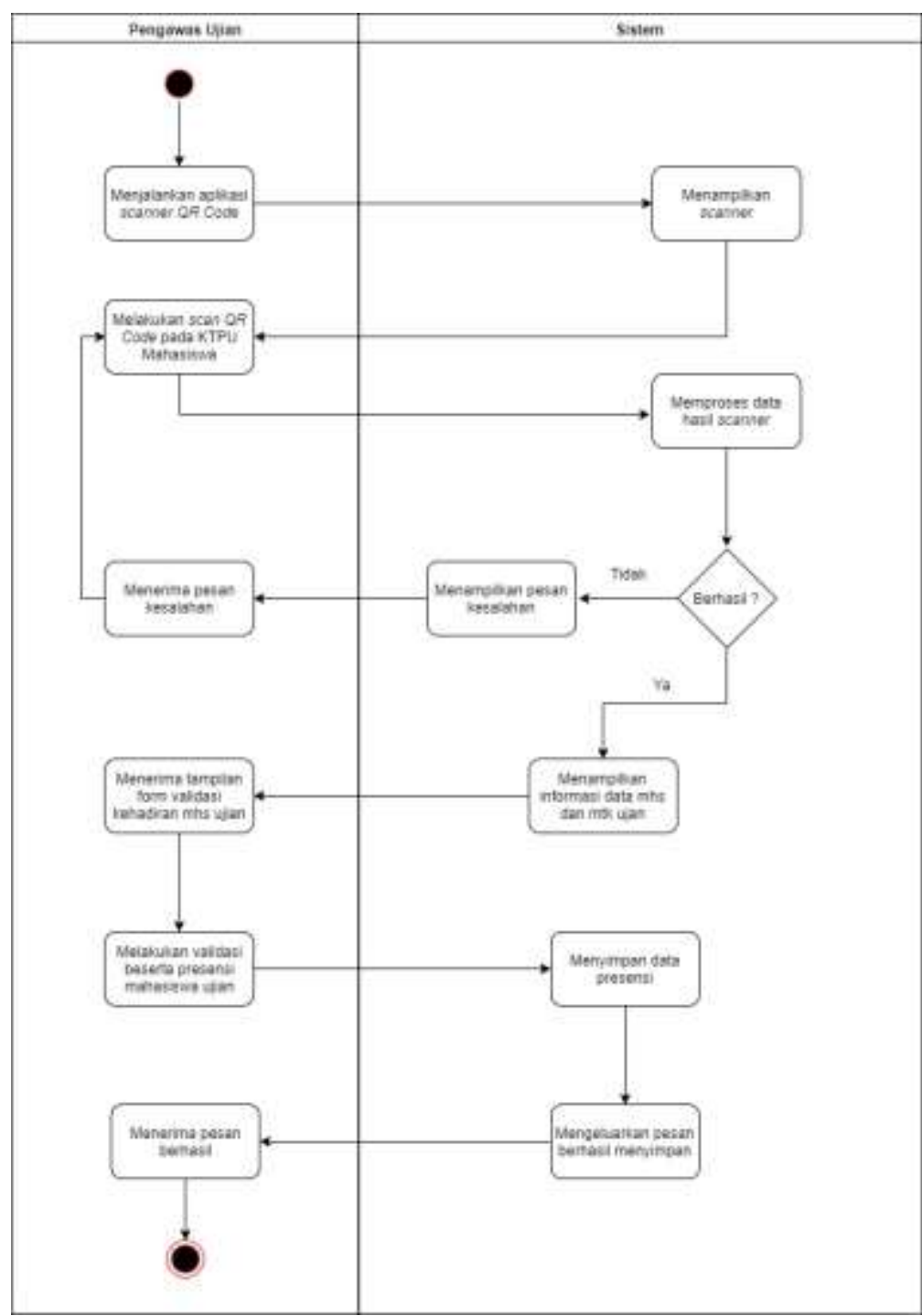

Gambar 4. Activity diagram validasi mahasiswa ujian

\section{Tampilan Layar Interface}

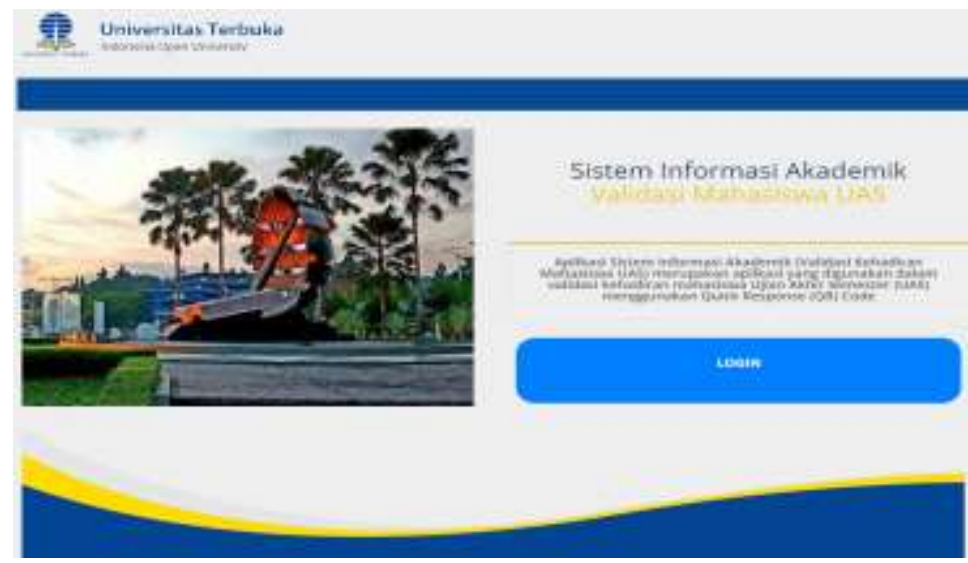

Gambar 5. Tampilan Halaman Dashbard 
Jurnal Riset dan Aplikasi Mahasiswa Informatika (JRAMI)

Vol 미 № 이 Tahun 2020

e-ISSN : $2715-8756$

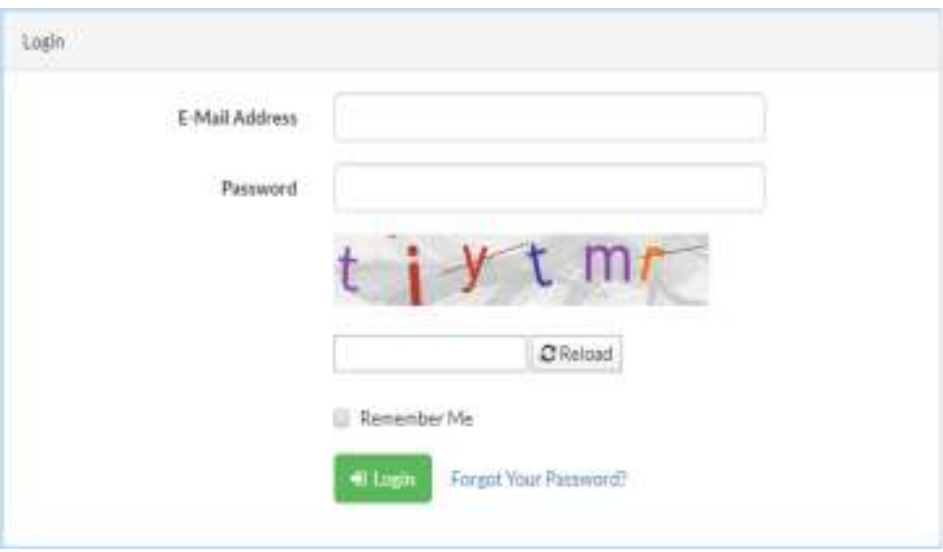

Gambar 6. Tampilan Halaman Login

\section{QR Scanner KTPU}

\section{[ ] SCAN KTPU MAHASISWA}

Gambar 7. Tampilan Form Scan QR Code

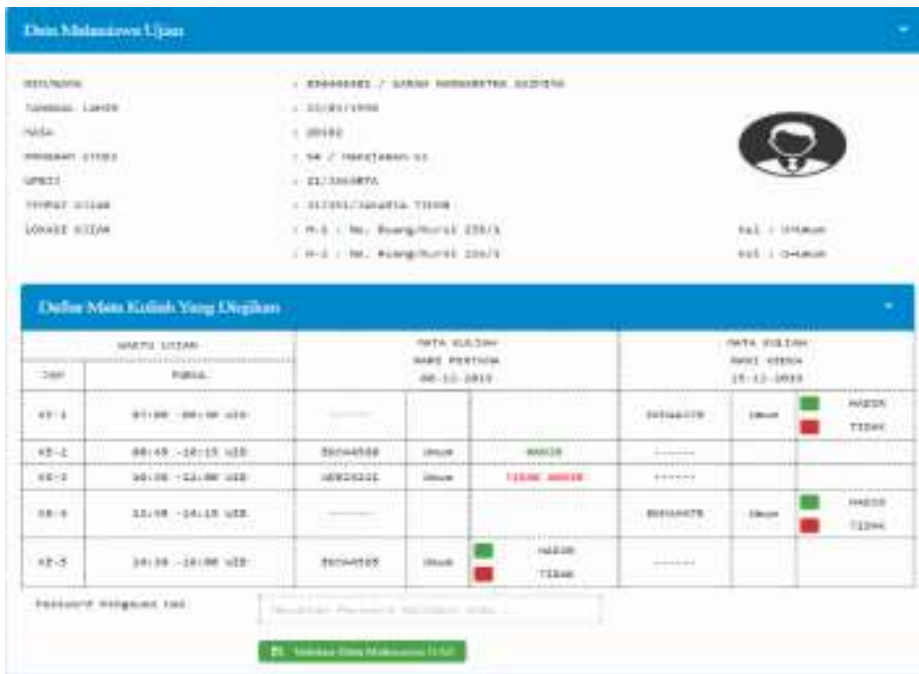

Gambar 8. Tampilan Form Validasi Mahasiswa Ujian 


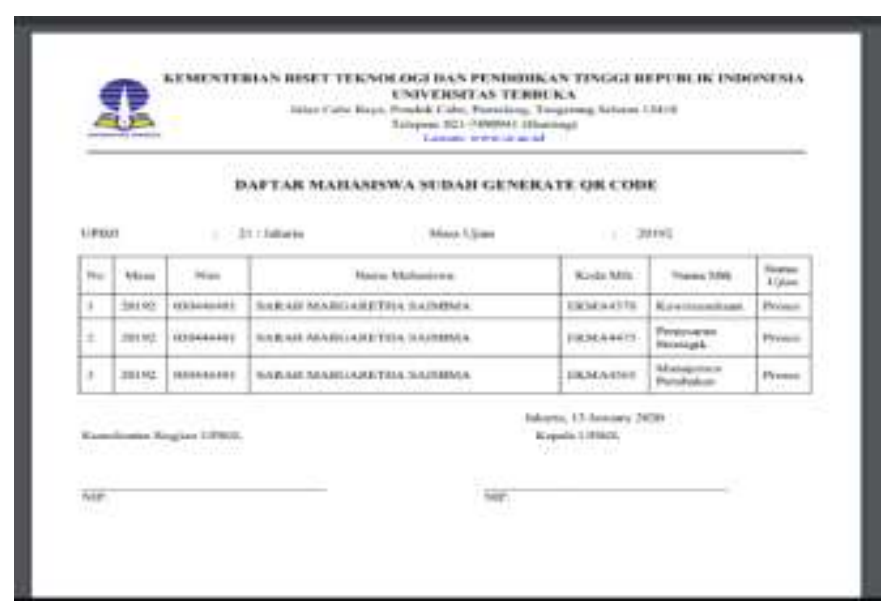

Gambar 9. Tampilan Laporan Generate $Q R$ Code

\section{SIMPULAN}

Berdasarkan hasil pembahasan mengenai "Sistem Validasi Kehadiran Mahasiswa dalam Ujian Akhir Semester (UAS) Universitas Terbuka Menggunakan Quick Response (QR) Code", Maka peneliti menarik simpulan sebagai berikut:

1. Dengan adanya sistem ini, maka masalah pelanggaran tata tertib Ujian Akhir Semester (UAS) berupa joki (orang yang mengerjakan ujian untuk orang lain dengan menyamar sebagai peserta ujian yang sebenarnya dan menerima imbalan uang) dalam pelaksanaan Ujian Akhir Semester (UAS) Universitas Terbuka dapat meningkatkan akurasi kehadiran dan mengurangi celah kecurangan berupa joki.

2. Dengan adanya sistem ini, masalah mahasiswa tidak membawa kartu identitas sehingga menyulitkan proses validasi peserta ujian pada saat pelaksanaan Ujian Akhir Semester (UAS) teratasi dengan adanya Quick Response (QR) Code.

3. Dengan adanya sistem ini, mempermudah Pengawas Ujian dalam melakukan validasi kehadiran Mahasiswa pada saat Ujian Akhir Semester (UAS) beserta presensi secara real time.

\section{DAFTAR PUSTAKA}

Nurrohman, A. L., Ciptaningtyas, H. T., \& Sunaryono, D. (2017). Rancang Bangun Sistem Validasi Kehadiran Perkuliahan dengan Metode K-Nearest Neighbor Berbasis Aplikasi Perangkat. Jurnal Teknik ITS, 6(2).

Tyanurani, N. (2013). Komposisi Aspek Berbahasa dan Bersastra pada Soal Ujian Akhir Semester. Journal of Chemical Information and Modeling, 53(9), 1689-1699.

Wijaya, A., \& Gunawan, A. (2016). Penggunaan QR Code Sarana Penyampaian Promosi Dan Informasi Kebun Binatang Berbasis Android Adiguna Wijaya 1), A. Gunawan 2) Teknik Informatika, STMIK Nusa Mandiri 1), Manajemen Informatika, AMIK BSI Sukabumi 2). Jurnal Bianglala Informatika, 4(1), 16-21.

Yudhanto, Y., \& Prasetyo, H. A. (2019). Mudah menguasai framework laravel. Elex Media Komputindo.

Yuni, S. (2013). Analisa dan Perancangan UML. Graha Ilmu. 